Hypothesis

\title{
Serendipity and the Brain, or How We Make Great Discoveries
}

\author{
Daniel Kondziella ${ }^{1,2, *}$
}

1 Department of Neurology, Rigshospitalet, Copenhagen University Hospital, Copenhagen, Denmark
2 Department of Clinical Medicine, University of Copenhagen, Copenhagen, Denmark
* Correspondence: daniel_kondziella@yahoo.com; Tel.: +45354563 68

\begin{abstract}
Serendipity favors the prepared mind, but how does the brain make that lucky find? Analyzing the cerebral mechanisms behind an exceptional (albeit trivial) discovery, the author suggests that a combination of 'concept cells' and the Global Neuronal Workspace Hypothesis could explain how we make great discoveries.
\end{abstract}

Keywords: concept cells; consciousness; Global Neuronal Workspace Hypothesis

Serendipity is an unplanned fortunate discovery [1]. More specifically, serendipity requires a certain mindset that makes it possible to instantly see the meaning of a particular event that others without that mindset would overlook or disregard as irrelevant. Louis Pasteur (1822-1895) captured this concept elegantly when he stated that "chance favors the prepared mind" [2]. Serendipity plays a role in many great scientific discoveries, notably in medicine [3].

The prototypical example of a serendipitous discovery is perhaps also the most important ever made in the field of medicine [4]: Returning from a family vacation to his laboratory at St. Mary's Hospital in London, Sir Alexander Fleming (1881-1955) found that a culture of staphylococci was contaminated with a fungus, which had resulted in a halo of bacteria-free area surrounding the fungus in the Petri dish. Anyone else would have thrown the Petri dish in the trash, but Sir Alexander Fleming immediately understood the implications of this finding, which led to the discovery of penicillin:

"One sometimes finds what one is not looking for. When I woke up just after dawn on September 28, 1928, I certainly didn't plan to revolutionize all medicine by discovering the world's first antibiotic, or bacteria killer. But I suppose that was exactly what I did [5]."

I, too, made a serendipitous discovery (though an infinite number of orders of magnitude less important).

On the way to work, I found a fossil (Figure 1). It is the rostrum of a belemnoid which belongs to an extinct group of marine cephalopods, not unlike modern squids, and lived in the Jurassic and Cretaceous periods. Given that I found it in Denmark, it probably stems from the Cretaceous period and is between 145 and 66 million years old. Fossils like this are colloquially called thunderstones because people in ancient times believed they were created by lightning. 

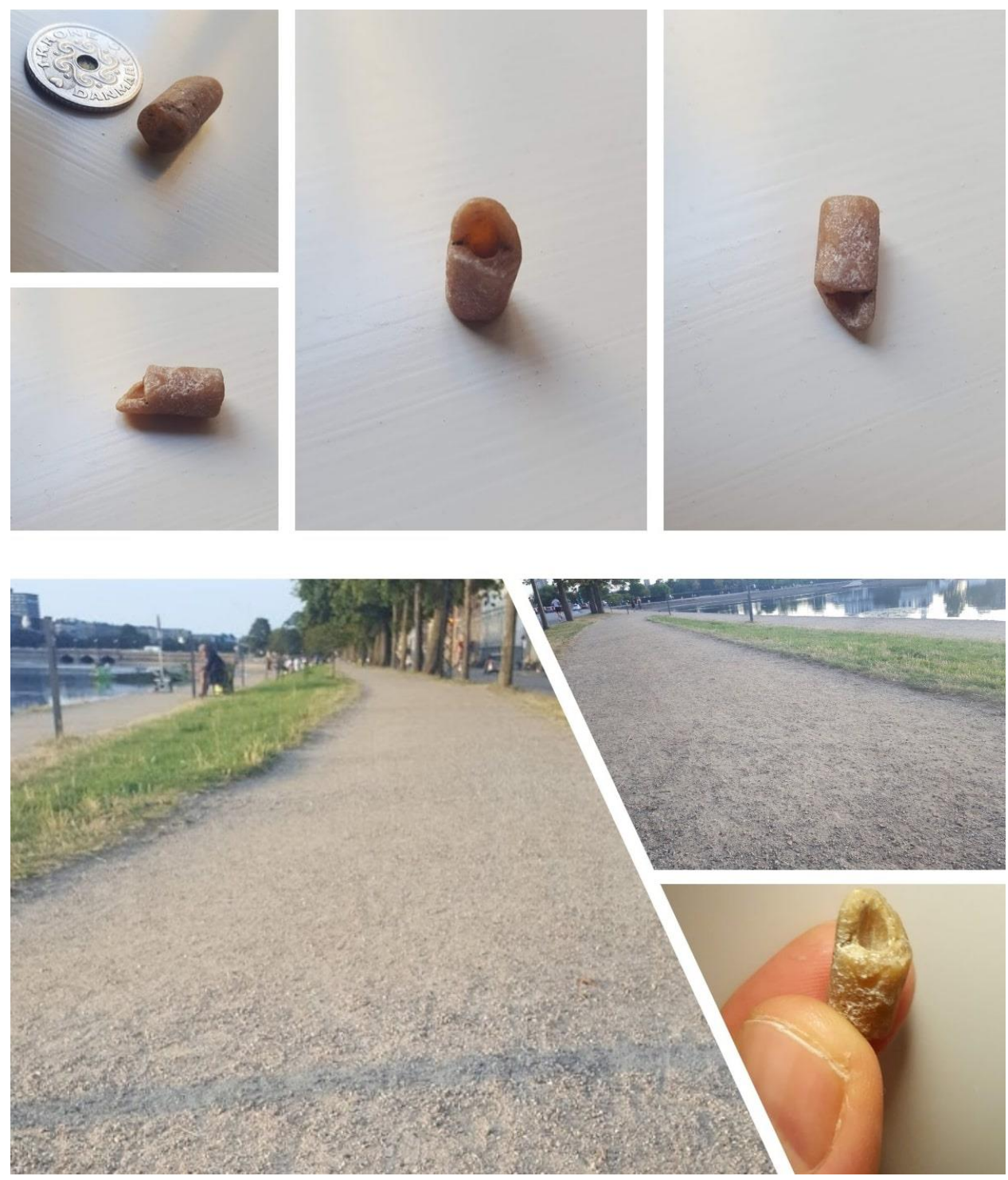

Figure 1. Top row. Belemnites are very common fossils. What remains of the squid-like animal is the petrified pencil or bullet-shaped shell, including the alveolus. This is a pretty unspectacular find, unless you are a paleontologist wannabe. Bottom row. The gravel path on which the find was made. In the upper left corner is my workplace, Rigshospitalet, Copenhagen University Hospital. Note the seemingly endless number of dust-covered small stones of the same size as the fossil.

Thunderstones are very unspectacular from a scientific point of view, but the neurologically interesting question is: How did I spot this tiny stone on a gravel path in the middle of a fairly large city, despite being in a hurry and my mind completely occupied with other things?

The explanation, I suggest, is a combination of the Global Neuronal Workspace Hypothesis [6] and 'concept cells' [7].

The Global Neuronal Workspace Hypothesis proposes that consciousness results from the global transmission of information throughout the brain, in particular fronto-parietal networks, and that a neuronal signal must reach a salience threshold to break through the background noise and 'ignite' a thought [8]. The salience of the object I found is caused by my fascination for paleontology, arguably the only field in academia that is as exciting as the human neurosciences. 
The notion of 'concept cells', also known as 'Jennifer Aniston neurons', comes from intracranial recordings made in surgery candidates with intractable epilepsy, showing that neurons in the medial temporal lobe which are at the distal end of the ventral stream fire in a remarkably selective way when seeing particular persons or objects, such as pictures of a famous American actress [9].

I thus suggest that a dedicated 'thunderstone neuron' in my medial temporal lobe fired a signal that reached the salience threshold necessary to ignite a conscious thought, which led to the discovery of the fossil. Because I stopped after 2 steps to turn around and look for it, we can calculate the approximate time it took for the concept cell to ignite a thought: Given my height $(185 \mathrm{~cm})$ and a brisk walking speed of perhaps $6.5 \mathrm{~km} / \mathrm{h}$ (I was in a hurry), my average stride length is about $80 \mathrm{~cm}$ (male; $0.43=$ =stride length/height), which means that 2 steps take $\approx 886$ milliseconds. This would be the time needed for the neuronal signal to travel along the visual stream, evoke firing of the concept cell and ignite the Global Neuronal Workspace (disregarding the top-down motor information that had me stop walking, half-way through the next step).

In conclusion, my brain spotted the fossil because its thunderstone neuron fired and for a few milliseconds made the rest of the global neuronal workspace keep quiet. Similar mechanisms may be at play when more important discoveries are made, including Sir Alexander Fleming's penicillin.

\section{References}

1. https://dictionary.cambridge.org/dictionary/english/serendipity, (n.d.).

2. Debré P. Dans les champs de l'obsérvation le hasard ne favorise que les ésprits préparés. (Louis Pasteur, 1822-1895), in: Louis Pasteur. Johns Hopkins Univ. Press. Balt., 1998: p. 1st. ed.

3. Ban, T. A., The role of serendipity in drug discovery. Dialogues Clin. Neurosci 2006, 8, 335-344. https://doi.org/10.31887/dens.2006.8.3/tban.

4. Wennergren, G.; Lagercrantz, H. "One sometimes finds what one is not looking for" (Sir Alexander Fleming): the most important medical discovery of the 20th century. Acta Paediatr 2007, 96, 141-144. https://doi.org/10.1111/j.16512227.2007.00098.x.

5. Tan, S. Y.; Tatsumura, Y. Alexander Fleming (1881-1955): Discoverer of penicillin. Singapore Med J 2015, 56, 366-367. https://doi.org/10.11622/smedj.2015105.

6. Mashour, G.A.; Roelfsema, P.; Changeux, J.P.; Dehaene, S. Conscious Processing and the Global Neuronal Workspace Hypothesis. Neuron 2020, 105, 776-798. https://doi.org/10.1016/j.neuron.2020.01.026.

7. Quiroga, R.Q. Concept cells: the building blocks of declarative memory functions. Nat Rev Neurosci, 2012, 13, 587-597. https://doi.org/10.1038/nrn3251.

8. Dehaene S.; L. Naccache. Towards a cognitive neuroscience of consciousness: basic evidence and a workspace framework. Cognition 2001, 79, 1-37.

9. Quiroga R.Q.; Reddy, L.; Kreiman, G.; Koch, C.; Fried I. Invariant visual representation by single neurons in the human brain. Nature 2005, 435, 1102-1107. 